\title{
A Study on the Problems and Countermeasures of the Development of Rural Ecotourism in China
}

\author{
Zhuang Chen \\ School of Economics and Finance, Huaqiao University, Quanzhou, Fujian \\ Email: 1024925876@qq.com
}

\begin{abstract}
In the new era, in China, urbanization is constantly making progress, and the boundaries between the urban and rural areas are increasingly blurred. From an economic perspective, the concept of rural ecotourism is currently emerging. In this paper, the issues in rural ecotourism development is taken as the starting point, and the purpose is to come up the with right solutions for the corresponding issues in order to implement the sustainable development and virtuous circle of rural ecotourism through measures including system improvement, local conditions, cultural integration, brand building, talent development, and the Internet, etc. thus achieving the major strategic goal of wellbeing of the people and the protection on the ecological environment.
\end{abstract}

Keywords: Rural ecotourism, problem analysis, path research

\section{Introduction}

With the continuous development of the social economy and urbanization progress, according to the statistics from the National Bureau of Statistics, in 2017, the urbanization rate of China has reached $58.52 \%$ nationwide. The implementation of the "Rural Revitalization" strategy includes the establishment of a sound urban-rural integration development mechanism and policy system and the acceleration of the modernization of agriculture in rural areas. Therefore, an increasing number of people are eager to go back to nature, experience the charm of primitive ecology, and seek communication with the rural.

Rural ecotourism is a class of ecotourism in which the idyllic scenery and humanity of rural areas attract tourists to enjoy vacations and experience a unique lifestyle with the premise of optimal allocation and integration of rural economic resources and environment. It is a new rural economic development model that integrates leisure, entertainment, culture, tourism, health, and therapy [1]. And it is an important way of implementing the rural revitalization strategy.

\section{Development Context of Rural Ecotourism}

At present, China's rural ecotourism has been rapidly developing under the ongoing urbanization progress, rural transformation, and rising consumption demand of tourism. The rural revitalization strategy can also be considered as policy support, which creates enormous potential for the development of rural ecotourism.

\subsection{Accelerated Urbanization}

Urbanization refers to the process in which rural population changes into urban population. Urbanization is an important aspect and an inevitable trend of modernization. However, the urbanization standard of China still lags far behind that of the developed countries. There are currently severe challenges in China's urbanization. The central business districts built with reinforced concrete are literally the same, with blind expansion and rapid population agglomeration, which has made it difficult for the agricultural population relocated to cities to integrate into urban life. Therefore, more and more people choose trips returning to nature, which promotes the rapid development of ecotourism in China. 


\subsection{Gradual Rural Transformation under the Opportunity of Rural Revitalization}

After forty years of reform and opening up, China has reached a critical period for economic transformation. Some polluting industries for cities and rural areas have been eliminated and the idea that good ecology means wealth is gradually gaining popularity. According to the statistics of the National Tourism Administration in 2017, the overall contribution of the national tourism industry to GDP was 9.13 trillion-yuan, accounting for $11.4 \%$ of the total GDP. Therefore, the tourism industry that brings benefits to the future generations should be the development path that the rural should first seek, and it should also be the focus of economic development in rural areas in the future under the strategic layout of "rural revitalization". It is helping the effective settlement of the issues of agriculture, farmer and rural area and outlines a new mission to agricultural and rural farmers in the context of rural revitalization in the new era.

\subsection{Expanding Demand for Tourism}

On one hand, due to the in-depth development of the social economy, the per capita disposable income of Chinese residents is increasing each year. The data from the National Bureau of Statistics shows that the per capita disposable income has reached 28,228 yuan in 2018, which is 2.3 times that of 2010. As a result, the demand for cultural activities and entertainment has been continuously improved. The statistics of the National Tourism Administration shows that the total number of visitors of China's rural tourism in 2017 was about 2.5 billion, with a year-on-year increase of $27.3 \%$. On the other hand, the accelerating pace of life puts increasing pressure on people's mental health. Therefore, people tend to choose to return to nature during leisure time, relieving themselves from pressures.

\section{Issues of the Development of Rural Ecotourism}

The rapid development of rural eco-tourism also exposes many issues affecting sustainable development, including weak brand effect, lack of institutional supervision, underdeveloped infrastructure construction, severe pollution, etc. If these issues cannot be solved in time, they will definitely restrict the healthy development of rural ecotourism.

\subsection{Failure to Establish a Good Brand}

Currently, due to the lack of established propaganda channels of rural eco-tourism and the lack of diversity in the forms of tourism, in many places, there have not been any good brands of rural tourism established. People are not impressed by the content of ecotourism. In addition, there are great variances in the standards of rural eco-tourism markets in different places in China, and the brand war has not yet started. Furthermore, since the rural eco-tourism markets are generally developing without proper cooperation, the markets have not established any sound relationship with tourism agencies, which, in addition to the lack of propaganda channels, makes it is difficult to form a brand effect [2]. Therefore, there has not been any rural ecotourism that is extremely popular. As more and more people are pursuing high-quality tourism, it is certain that branding will be the focus of competition in rural eco-tourism markets in the future.

\subsection{Insufficient Regulation of Rules and Laws, Lack of Tourism Supervision}

With the rise of rural eco-tourism, facilities like hotels that have distinctive local and cultural features all cater to the tourists' needs. However, due to the facts that the legal status of homestay has not been clearly defined and other infrastructures lack specific standards for enforcement in terms of security, fireproof measures, and sanitation, the rural ecotourism markets are still in a state of disorder.

The rural ecotourism markets also display the feature of spontaneity, but currently, there have been a lot of cases of defects like impractical application arising in the rural ecotourism system, which makes the markets unable to keep pace with the general trend. Staying on the traditional level but wanting to plan the current complex rural eco-tourism is obviously unrealistic. Although the government puts great incentives on the development of rural ecotourism, there has not yet been any specific system that is 
able to assist in managing and refining the development of rural ecotourism. Which means there is literally no laws or regulations and no direct association with the laws of rural ecotourism in this regard. This results in various risks during development. It is precisely because of the inadequate relevant laws and regulations of rural ecotourism and the lack of strength of relevant departments that some rural ecotourism operators can do the business illegally.

\subsection{Underdeveloped Rural Ecotourism Infrastructure}

The economic and education levels of rural ecotourism spots are generally low. Especially, without the focus on the development and construction of tourist traffic routes, traffics at rural eco-tourism attractions are not convenient enough; the traffics to the places of ecotourism are generally long and difficult, and in some cases, even special means of transportation should be used. However, the construction of such special means of transportation is still underdeveloped. Meanwhile, basic facilities like accommodation, catering, entertainment, etc. are also extremely scarce. As modern tourists put more emphasis on tourism experience enjoyment, it is not enough for ecotourism operators to rely solely on unique natural resources.

\subsection{Severe Damage to the Ecosystem and Emerging Environmental Issues}

The purpose of many tourists who choose rural ecotourism is to enjoy the natural landscape, the local customs and the leisure of vacation. However, due to inadequate tourism management and people's weak awareness of the protection of the natural environment. Some of the spots are not cleaned up in time, and there are various types of pollution. Due to the low consumable nature of natural scenery and the high vulnerability of ecosystems, single minor damage is often enough to bring irreversible damage to the ecology. In some places, the ecotourism operators ignore the need of visitors to appreciate the original ecology of pure natural scenery, and create artificial landscapes, which not only severely affects the tourists' experience, but also destroys the unity and harmony of the original ecology.

\section{Research on the Development Path of Rural Ecotourism}

In view of the above issues of rural ecotourism development, the purpose is to come up the with right solutions for the corresponding issues in order to implement the sustainable development and realize virtuous circle of rural ecotourism through measures including system improvement, local conditions, cultural integration, brand building, talent development, and the Internet, etc. thus achieving the major strategic goal of wellbeing of the people and the protection on the ecological environment.

\subsection{Improve the Legal System on Rural Ecotourism and Enhance Tourism Supervision}

\subsubsection{Improve relevant laws and regulations}

Introduce new laws for the current conditions. Based the compilations of laws on the five development concepts including innovation, coordination, environmental friendliness, openness, and sharing. Establish a legal system for sustainable rural ecotourism by further improving the natural resources law, development planning law, tourism law, environmental protection law, etc. Combine existing laws with rural ecotourism. Implement the idea of sustainable development, respect the laws of nature, and control development within a reasonable range of environmental tolerance.

\subsubsection{Enhance supervision enforcement}

Impose legal sanctions on the illegal acts including deliberately destroying the rural ecotourism order, damaging the ecological environment, or destroying the natural resources. The government should enhance the macro-level management of rural ecotourism development and formulate corresponding policies to limit the vicious behaviors and promote the healthy and steady development of the industry.

\subsubsection{Establish a sound system that integrates development, management, and evaluation}

Based on the industry policies and supplemented by the supporting system, establish the relatively independent supervision institutions and mechanisms to define the functions and obligations and rights of the supervisory institutions in a legal form. Establish and improve supervision mechanisms, including the approval and monitoring system for rural ecotourism projects as well as the environmental tourism 
environmental certification system. Also, the relevant departments responsible for rural tourism development can hold social hearings established by the government, etc. It is also possible to rely on online monitoring with cloud computing and big data.

\subsection{Adapt to Local Conditions to Build Brand with Regional Culture Features}

\subsubsection{Adapt to local conditions and avoid generalization or stereotype}

To develop rural ecotourism, it is necessary to promote rural development by classification. According to the Rural Revitalization Strategic Plan (2018-2022), traditional villages are categorized into four types: concentrated industrial villages (specialized villages), characteristic protection villages (historical and cultural villages, traditional villages, ethnic minority villages, characteristic landscape tourist villages, and other villages with rich natural and historical resources), suburban fusion villages, relocation and emigration villages. It is necessary for the first two types of villages to carry out ecotourism development management; for the latter two types of villages, it is necessary to integrate into cities or to implement relocation, instead of making a generalization.

\subsubsection{Highlight local culture features}

Starting from cultural innovation, improve the cultural connotation in rural ecotourism and focus on the construction and development of special tourism products. Work hard to excavate, collect, organize, and publicize traditional rural culture carriers, including ancient village architectures, traditional folk crafts, featured snacks, traditional village customs, etc. Integrate modern elements into the existing cultural carriers, bravely conduct cultural innovation activities and develop cultural and creative products. Meanwhile, integrate the humanity landscape into the natural landscape, and integrate the cultural and historical connotation into the humanity landscape [3].

\subsubsection{Focus on shaping high-quality brands}

First, focus on openness and develop with high-quality virtues. Tightly grasp the opportunity of "one village, one product" of beautiful village construction. Make use of the unique local conditions and natural resources focus on building brands, and through reasonable planning, rational distribution, integration of various rural eco-tourism resources, enhance propaganda, focus on building good images and increase the brand awareness.

\subsection{Develop Rural Ecotourism Infrastructure}

Rural ecotourism areas are different from urban tourism. The remote geographical location and the inconvenient traffic makes it important to build transportation facilities in rural ecotourism areas. For instance, enhance the construction of tourist traffic signage guidance system, set up key scenic spot guide signboards at major intersections, and focus on the update and upgrade of tourism guide signboards to facilitate self-driving traveling. With the radiation development of traffic network, comprehensively improve the roads and ways connecting the scenic spots, build a complete tourism transportation network integrating roads, railways, waterways, and flights, and develop rural ecotourism areas along the ways. Meanwhile, improve the tourist reception facilities, including accommodation, catering, power supply, water supply, gas supply, communication, parking, garbage and sewage treatment, etc.

\subsection{Focus on Rural Environmental Protection and Achieve Sustainable Development}

When developing rural ecotourism, it is necessary to follow the principles of the combination of development and protection to avoid blind development and destructive construction behaviors. During the development process of rural ecotourism resources, we should preserve the original natural scenery so that the natural and artificial beauties can be organically combined to facilitate balanced and harmonious development. These artificial transformations should be appropriate and reasonable, to avoid destroying the original natural scenery. It is necessary to continuously improve the sustainable utilization and attractiveness of natural resources to provide a guarantee for the subsequent development and deployment. In business management, it is necessary to extend the rural eco-tourism industry chain as much as possible, abandon the destructive and one-time consumption behaviors in the 
past, and build an integrated rural eco-tourism service model to meet the comprehensive needs of consumers [4].

\subsection{Introduce and Develop Relevant Talents and Make Full Use of the Internet}

\subsubsection{Establishing a talent introduction and cultivation mechanism}

Attract more talents to go to the rural and reserve talents for rural ecotourism through various measures. First, put more efforts in developing professionals in farming; second, enhance the education of professional talents for rural development; third, make good use of the support from scientific and technological talents; fourth, encourage all sectors of society to participate in rural construction; fifth, innovate the mechanisms of the introduction and use of talents for rural development.

\subsubsection{Establishing the "Internet Plus Rural Ecotourism" model [5]}

Under the traditional management model of tourism, establish an Internet Plus rural ecotourism model by conforming to the current development trend of the Internet, big data, and cloud computing [6]. First, rural ecotourism scenic spots and the businesses can make use of the Internet for publicity, and the construction of ecotourism projects can also rely on the Internet, for tasks including planting agricultural products, promoting cultural and creative products, etc. Second, relevant government departments should regulate the operation of scenic spots and business operations by establishing an evaluation system on complaints and suggestions from the tourists and by using the ecological monitoring systems and environmental warning systems, etc. Finally, through the second-time publicity by the tourists who have already visited the spots, further enhance the popularity of the scenic spots. These measures enable the government, merchants, ecotourism operators, and tourists to interact effectively.

\section{References}

1. Hu Manfei. The Development of Rural Ecotourism Under the Context of Internet Plus [J]. Resort tourism, 2018(10):171-173.

2. Zhang Changwei. Discussion on the Strategy of Environmental Protection for Rural Ecotourism [J]. Journal of Green Science and Technology, 2018(18):136-137.

3. Guo Zhimin. Study on the Interactive Development of Rural Construction and Ecotourism [J]. Northern Economy, 2017(04):71-73.

4. Wang Xiaodi. The Realistic Dilemma and Development Path of the Rural Ecotourism Industry in China [J]. Agricultural Economics, 2017(11):44-46.

5. Liu Shuang, Wang Jinghan. Research on the Path of Diversified Tourism Mode in Promoting Rural Revitalization [J]. Management Observer, 2018(23):59-61.

6. Yang Hong. Development Strategy Analysis of Rural Ecotourism in the Internet Plus Era [J]. Tourism Overview (Semimonthly), 2018(08):169.

7. Ar Nima. Exploring the New Model of "Agriculture + Culture + Ecotourism" [N]. Dong Fang Cheng Xiang Bao, 2018-09-11(A02). 